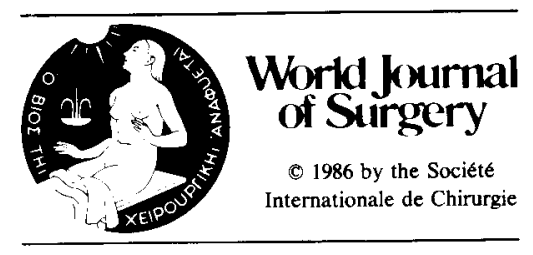

\title{
Total Thyroidectomy: Complications and Technique
}

\author{
Jay K. Harness, M.D., Lit Fung, M. D., Norman W. Thompson, M.D., Richard E. Burney, M.D.,
} and Michael K. McLeod, M.D.

Department of Surgery, University of Michigan, Ann Arbor, Michigan, U.S.A.

During the 27-year period from 1957 to 1984 , four hundred thirty patients underwent total thyroidectomies for malignant or benign disease of the thyroid gland at our institutions. Thyroid cancer was found in $\mathbf{8 3 . 4 \%}$ of cases, and 47.2\% of these had concomitant lymph node dissections. Transient recurrent laryngeal nerve injury occurred in 6.2\% of the entire series. Permanent unilateral vocal cord paralysis occurred in $2.5 \%$ of the patients operated on, although only 1 patient $(0.45 \%)$ sustained this complication in the past 14 years. No patient had permanent bilateral vocal cord paralysis. Transient hypoparathyroidism was seen in $16.8 \%$ of patients with permanent hypoparathyroidism occurring in $4.0 \%$. The incidence of permanent hypoparathyroidism fell to $2.7 \%$ during the past 14 years and was directly related to the extent of thyroid cancer found at operation. Postoperative complications decrease with the experience of the surgeon and increase with reoperations and extensive disease. Total thyroidectomy continues to be our treatment of choice for thyroid cancer.

Total thyroidectomy has been the mainstay of treatment for nearly all primary malignant lesions and certain benign conditions of the thyroid gland at our medical center for the past 27 years. The extent of thyroid gland removal at operation has been widely debated because more extensive operative procedures carry with them potentially increased complications. Those advocating total thyroidectomy for carcinoma feel that this procedure decreases total recurrence, facilitates the detection and treatment of differentiated tumors with ${ }^{131} \mathrm{I}$, improves the rate of long-term survival, and is associated with only a

Reprint requests: Jay K. Harness, M.D., Department of Surgery, 2920F Taubman Health Care Center Box 0331, 1500 E. Medical Center Dr., Ann Arbor, Michigan 48109, U.S.A. slight increase in risk as compared with near-total thyroidectomy. The risks are accepted as a fair trade-off for decreased long-term mortality.

The technique of thyroidectomy has been in evolution for many years. Classic articles by Kocher, Halsted, Lahey, Crile, and Riddell have provided surgeons with principles that have significantly reduced operative morbidity and mortality from thyroidectomy [1-5]. The major complications directly attributed to total thyroidectomy are permanent hypoparathyroidism and recurrent laryngeal nerve injury, particularly if such injury involves the nerve contralateral to a primary tumor. The reported incidence of permanent recurrent laryngeal nerve injury has varied from $0 \%$ to $14 \%$ and, for permanent postoperative hypoparathyroidism, from $1.2 \%$ to $11 \%$ [6-15]. The occurrence of hypoparathyroidism and recurrent laryngeal nerve injury after total thyroidectomy has been attributed to operative technique, extent of the thyroid neoplasm, previous thyroid operations, concomitant lymphatic dissections, and other factors such as anatomic variability and vulnerability of the recurrent laryngeal nerves.

This study was undertaken to update our previous report on the complications of total thyroidectomy and to determine what factors continue to impact the overall operative morbidity [6].

\section{Materials and Methods}

During the 27-year period from January 1957 through June 1984, four hundred thirty patients underwent total thyroidectomies for malignant or benign disease of the thyroid at the University of Michigan Affiliated Hospitals (University Hospital, Ann Arbor; Veterans Administration Medical Center, Ann Arbor; Wayne County General Hospital, 
Table 1. Histologic classification of excised thyroid glands (1957-1984).

\begin{tabular}{lc}
\hline & Patients \\
\hline Papillary carcinoma & ${ }^{a}$ \\
Follicular carcinoma & 226 \\
Medullary carcinoma & 65 \\
Hurthle cell carcinoma & 21 \\
Anaplastic carcinoma & 16 \\
Multinodular goiter & 9 \\
Hashimoto's thyroiditis & 27 \\
Graves'disease & 10 \\
$\quad$ Total & 30 \\
\hline
\end{tabular}

${ }^{a}$ Includes follicular varient of papillary carcinoma.

Westland, Michigan). The records of 404 patients were available for retrospective review and analysis of technique of the operation performed, extent of the disease, pathologic findings of excised tissue, degree of recurrent laryngeal nerve injury, degree of postoperative hypoparathyroidism, other perioperative complications, and mortality.

Total thyroidectomy is defined as the surgeon's attempt to perform an extracapsular removal of the entire thyroid gland including pyramidal lobe while preserving the parathyroid glands, recurrent laryngeal nerves, and external branches of the superior laryngeal nerves. Recurrent laryngeal nerve injuries were considered accidental complications of technique unless vocal cord paralysis was observed preoperatively or the operating surgeon specifically indicated that nerve excision was necessary to assure removal of the neoplasm. In the last 14 years of the study, more functioning nerves were left in situ, despite extensive disease, and well-differentiated carcinoma was "shaved" off the nerves to avoid their sacrifice. If these nerves failed to function postoperatively, these were not considered accidental injuries. Recurrent laryngeal nerve injury was documented by either direct or indirect laryngoscopy. In all patients, persistent hypoparathyroidism was considered to be a direct result of the technique unless the patient had preoperative hypocalcemia. Postoperative hypoparathyroidism and vocal cord paralysis lasting 1 year or longer were considered permanent; however, if recovery occurred before that time, they were considered transient. Only clinically symptomatic patients were treated for their hypocalcemia. Records of all operations were carefully reviewed for details of surgical technique and the extent of tumor involvement. These factors were correlated with operative complications. All patients with differentiated thyroid carcinomas underwent postoperative ${ }^{131}$ I scanning for documentation of the presence of residual thyroid tissue and/or metastases.

\section{Results}

During the 27-year period, all 404 patients underwent total thyroidectomies either as an initial operation in 264 patients $(65.3 \%)$ or as a completion thyroidectomy in 140 patients $(34.7 \%)$. Concomitant lymph node excisions ranging from local removal of 1 or more central compartment nodes to bilateral neck dissections were performed in 159 (47.2\%) of the 337 patients with thyroid cancer.

Table 1 outlines the histological classifications of the resected specimens for the entire series. Thyroid cancer was found in 337 patients $(83.4 \%)$ and other benign conditions in 67 patients $(16.6 \%)$. Total thyroidectomies were performed in the benign conditions listed for a variety of reasons including previous history of head and neck irradiation, associated suspicious nodules, Graves' eye disease, and children with Graves' disease.

Recurrent laryngeal nerve injuries are shown in Table 2. A comparison is made between our previously reported experience from 1957 through 1969 and our most recent experience from 1970 to mid-1984. All of the cases in our earlier experience had thyroid cancer, while our most recent experience includes both patients with cancer and the 67 patients with benign conditions. Transient nerve injury, lasting from a few days to 11 months, occurred in 25 patients $(6.2 \%)$ of the entire series, but in only 4 patients $(1.8 \%)$ in our last 220 cases. The incidence of permanent nerve injury for the entire series was $2.5 \%$; however, it was only $0.45 \%$ since 1970 . The incidence of recurrent laryngeal nerves invaded by tumor or deliberately sacrificed at operation remained remarkably constant for the entire period of the series at $6.9 \%$. One patient with a diffusely enlarged goiter had a right vocal cord paralysis preoperatively caused by traction on the nerve by the goiter. Nerve function recovered after thyroidectomy. No patients suffered permanent bilateral nerve injury. Four patients, however, required temporary tracheotomies for bilateral transient vocal cord paralysis. One additional patient, operated on since 1970, sustained accidental division of 1 branch of a recurrent laryngeal nerve which was immediately recognized and repaired primarily at the original operation. The patient had complete recovery of vocal cord function on the involved side within 6 months.

Transient hypoparathyroidism occurred from 1 day postoperatively and lasted up to 1 year, in 68 $(16.8 \%)$ of 404 patients (Table 3 ). Seventy-six symptomatic patients were treated with calcium and/or vitamin $D$ until their symptoms abated and their serum calcium returned to normal levels. Patients were considered to be permanently hypoparathyroid if they required treatment longer than 1 year. 
Table 2. Recurrent laryngeal nerve injury.

\begin{tabular}{|c|c|c|c|}
\hline & $\begin{array}{l}1957-1969 \\
\text { (184 patients) }\end{array}$ & $\begin{array}{l}1970-1984 \\
(220 \text { patients })\end{array}$ & $\begin{array}{l}\text { Total series } \\
\text { (404 patients) }\end{array}$ \\
\hline Transient injury & $21(11.4 \%)$ & $4(1.8 \%)$ & $25(6.2 \%)$ \\
\hline Permanent injury & $9(4.9 \%)$ & $1(0.45 \%)$ & $10(2.5 \%)$ \\
\hline Nerves invaded by tumor or sacrificed & $13(7.1 \%)$ & $15(6.8 \%)$ & $28(6.9 \%)$ \\
\hline
\end{tabular}

Table 3. Postoperative hypoparathyroidism.

\begin{tabular}{llll}
\hline & $\begin{array}{l}1957-1969 \\
(184 \text { patients })\end{array}$ & $\begin{array}{l}1970-1984 \\
(220 \text { patients })\end{array}$ & $\begin{array}{l}\text { Total series } \\
(404 \text { patients })\end{array}$ \\
\hline Transient & $24(13.0 \%)$ & $44(20.0 \%)$ & $68(16.8 \%)$ \\
Permanent & $10(5.4 \%)$ & $6(2.7 \%)$ & $16(4.0 \%)$ \\
\hline
\end{tabular}

Temporary hypoparathyroidism was treated for a mean duration of $25.5 \pm 20$ weeks. The overall incidence of permanent hypoparathyroidism for the entire series was $4.0 \%$; however, this fell to $2.7 \%$ for the last 220 patients. In this later subgroup, 5 of the 6 patients were found at operation to have extensive bilateral involvement by thyroid cancer. These patients had both local invasion and extensive nodal spread of their tumors. Only 1 patient sustained permanent postoperative hypoparathyroidism following total thyroidectomy for a localized cancer involving a single lobe. None of the patients undergoing total thryoidectomy for benign disease suffered permanent hypoparathyroidism.

Tracheotomies were done as an emergency procedure postoperatively in a total of 9 patients $(2.2 \%)$. Only 3 of these were done in the last 220 patients $(1.4 \%)$. A total of 3 patients $(0.74 \%)$ were returned to the operating room over the past 27 years for postoperative hemorrhage. This complication has occurred in only 1 of the 220 patients treated in the past 14 years $(0.45 \%)$. Drains were rarely used in this series and then only after nodal dissections in the lateral neck rather than the central compartment. Infections were rare $(0.5 \%)$ even though antibiotics were not used. In 1 patient, a cellulitis developed which was treated without drainage (antibiotics only). Another patient developed a Staphylococcus aureus infection between the superficial layer of the deep cervical fascia and the platysma muscle which was treated by opening and draining the center of the wound. The operative mortality rate for the entire series was zero. Any deaths from cancer of the thyroid occurred after the first 30 days postoperatively.

\section{Discussion}

The anatomy and vulnerability of the recurrent laryngeal nerves during thyroidectomy have been widely studied [16-18]. The complications of thyroidectomy for carcinoma increase with the extent of disease found at operation, with reoperative surgery, and with less experienced surgeons [6, $10-13,15]$.

The debate over the use of total thyroidectomy routinely for the treatment of all differentiated thyroid carcinoma continues. Total thyroidectomy has also been advocated for the treatment of certain benign conditions including extensive colloid nodular goiter, toxic nodular goiters, chronic thyroiditis, Graves' disease (especially in Graves' eye disease), and nodules associated with head and neck irradiation. Total thyroidectomy is perceived as a more hazardous operation primarily because of the additional risk to the contralateral recurrent laryngeal nerve and the potential risk of permanent postoperative hypoparathyroidism. Injury to the recurrent nerve on the side opposite a localized primary thyroid neoplasm is particularly unfortunate. Furthermore, there have been no series of cases with sufficient long-term follow-up to document statistically improved survival with total thyroidectomy in treating differentiated thyroid carcinoma.

With applied anatomic knowledge and improved techniques has come a reduction in the morbidity of total thyroidectomy. Jacobs et al. reported a $0 \%$ permanent recurrent laryngeal nerve injury rate in 213 patients undergoing total thyroidectomies using the same techniques as utilized in this series [10]. Scanlon and colleagues had 1 permanent nerve injury in 245 total thyroidectomies [12]. Karlan et al. reported a $0 \%$ nerve injury rate in 1,000 consecutive thyroid operations. Of these, 457 were total thyroidectomies, but only 93 were performed for malignancy [7]. Recent reports by Martensson and Ternins from Sweden and Starnes et al. from Boston have been most disturbing [14, 15]. Martensson reports a $14 \%$ incidence of permanent nerve injury after operations for thyroid cancer or reoperations for benign disease. Starnes reports an incidence of postoperative complications that was 20 times higher with total thyroidectomy than with partial thyroidectomy. The numbers of patients undergoing total thyroidectomies in both these series were small and their collective experience with total thyroidectomy was limited. 
Our own experience with recurrent laryngeal nerve injury, especially over the past 14 years, has been consistent with other large series covering similar time periods $[7,10,12]$. The marked decrease in transient nerve injuries from $11.4 \%$ in the first half of our series to $1.8 \%$ since 1970 is most gratifying. Similarly, our decreased incidence of permanent accidental nerve injury from $4.9 \%$ to $0.45 \%$ is equally rewarding. We believe that these improvements represent the full use by all of our colleagues at the University of Michigan of the techniques advocated by Thompson et al. in 1973 [19]. Only 1 patient sustained a permanent nerve injury in the last 14 years, and this was on the side opposite a primary tumor. Of the 10 cases of permanent nerve injury for our entire series, 4 occurred on the side opposite a primary neoplasm.

Wade, Loré, and Riddell have detailed the vulnerability of the recurrent nerve at the time of operation [16-18]. We particularly agree with Lore that the nerve is at greater risk of injury in the region of the posterior suspensory ligament of the thyroid (ligament of Barry) where the nerve often penetrates the ligament. This relationship was also detailed by Thompson et al. in 1973 [19]. We do not routinely identify the recurrent nerve early in the operative procedure as advocated by others [3, 4]. As a dissection proceeds to the area of the ligament of Berry, however, we typically identify the recurrent nerve as it courses close to or through the ligament. Routine identification of the nerve both initially and in the area of the ligament of Berry should be practiced by less experienced surgeons. Also, when the course of the recurrent nerve is difficult to follow because of extensive thyroid carcinoma in the central compartment, the nerve should be identified and traced from the thoracic inlet toward the larynx in order to prevent injury.

Injury to the external branch of the superior laryngeal nerves should be avoided by careful downward mobilization of the superior pole of the thyroid gland. Anterior and posterior branches of the superior thyroid vessels are individually ligated and divided as they course over the superior pole. This technique prevents injury to the external branch of the superior laryngeal nerves as they may course through the bifurcation of the superior thyroid vessels.

Nonrecurrent laryngeal nerves occur primarily on the right because of an anomalous right subclavian artery arising directly from the aorta which occurs with a frequency of $0.3-1.0 \%$ reported in the literature [20]. Theoretically, if the left subclavian were to arise from a right-sided dorsal aorta, it should be possible for an anomalous recurrent nerve to occur on the left side. Such a case was discovered in a dissecting room cadaver but has never been reported in the clinical literature [16]. Recently, Sanders and colleagues reported the first 2 cases of right-sided nonrecurrent laryngeal nerves in addition to standard recurrent nerves [21]. The importance of experience in thyroid surgery is again emphasized.

Since 1970, the reported incidence of permanent postoperative hypoparathyroidism following total thyroidectomy has varied from $1.2 \%$ to $11 \%[6-10$, $12,14]$. Prevention of ischemia to the parathyroid glands is of paramount importance in avoiding this complication. We take all branches of the inferior thyroid artery on the capsule of the thyroid gland medial to that artery's branches to the parathyroid glands in order to avoid compromised blood flow to the parathyroids. The parathyroid glands are themselves always carefully dissected away from the thyroid gland capsule starting at a point medial to their blood supply and gently teasing them laterally and posterior to the thyroid capsule. If a parathyroid gland is inadvertently devascularized, it may be immediately reimplanted in an adjacent sternocleidomastoid muscle.

The risk of hypoparathyroidism increases with reoperation and extensive thyroid carcinoma [6]. Nearly all of our cases of permanent hypoparathyroidism occurred in patients with extensive bilateral thyroid carcinomas that involved the central compartment and jugular lymph nodes and were associated with local invasion. Because of bilateral involvement and extensive local disease, nothing short of total thyroidectomy would have been acceptable therapy in these cases. Every effort should be made in such cases to identify the parathyroid glands and to preserve their blood supply. Vascularly compromised glands should be reimplanted. Despite the most careful operative technique, a small percentage of patients will suffer permanent hypoparathyroidism as a result of legitimate efforts to eradicate extensive disease and achieve cure. In our last 220 patients, permanent hypoparathyroidism occurred in 6 patients $(2.7 \%)$, all but 1 of whom had very extensive carcinoma.

Total thyroidectomy remains the treatment of choice for thyroid cancer in our experience because of its excellent control of local spread of disease and because it facilitates the postoperative use of ${ }^{131} \mathrm{I}$ therapy in those patients with extensive differentiated thyroid carcinomas. Its utility in the management of a variety of benign conditions of the thyroid gland is also noted. Postoperative complications are currently related primarily to secondary operations and extent of disease. They decrease with experience and meticulous attention to careful technique. 


\section{Résumé}

Au cours d'une période de 27 ans de 1957 à 1984 , quatre cent trente patients ont subi une thyroïdectomie totale dans notre établissement pour des lésions bénignes ou malignes du corps thyroïdien. Dans $83.4 \%$ des cas il s'agit d'un carcinome thyroïdien, nécessitant chez $47.2 \%$ d'entre eux un curage ganglionnaire associé. On observe une atteinte transitoire du nerf récurrent laryngé dans $6.2 \%$ des cas sur la totalité de la série. Une paralysie permanente unilatérale des cordes vocales survient chez $2.5 \%$ des patients opérés, alors que durant les 14 dernières années un seul patient présente cette complication. Aucun des cas de paralysie bilatérale permanente des cordes vocales n'est observé. Une hypoparathyroïdie transitoire est constatée chez $16.8 \%$ des patients avec hypoparathyroïdie définitive dans $4.0 \%$ des cas. L'incidence de l'hypoparathyroïdisme définitif tombe à $2.7 \%$ au cours des 14 dernières années et est directement liée à l'extension du cancer thyroïdien constaté lors de l'intervention. Les complications postopératoires diminuent avec l'expérience du chirurgien et augmentent lors des réinterventions et l'extension des lésions. La thyroïdectomie totale demeure pour les auteurs le traitement de choix du cancer thyroïdien.

\section{Resumen}

En el lapso de los 27 años entre 1957 y 1984, cuatro cientos treinta pacientes fueron sometidos a tiroidectomía total por enfermedad maligna o benigna de la glándula tiroides en nuestras instituciones. Cáncer tiroideo fue hallado en $83.4 \%$ de los casos, y $47.2 \%$ de éstos tuvieron disecciones ganglionares concomitantes. Lesión transitoria del nervio recurrente laríngeo ocurrió en el $6.2 \%$ de la serie total. Parálisis permanente unilateral de la cuerda vocal ocurrió en $2.5 \%$ de los pacientes operados, mientras sólo un paciente $(0.45 \%)$ presentó esta complicación en los últimos 14 años. Ningún paciente presentó parálisis bilateral permanente de las cuerdas vocales. Hipoparatiroidismo transitorio fue observado en $16.8 \%$ de los pacientes, y el hipoparatiroidismo permanente ocurrió en el $4.0 \%$. La incidencia de hipoparatiroidismo permanente descendió a $2.7 \%$ en los últimos 14 años y apareció directamente relacionado con la extensión del cáncer tiroideo hallada en la operación. Las complicaciones postoperatorias disminuyen en relación a la experiencia del cirujano y se incrementan con las reoperaciones y con la enfermedad muy extensa. La tiroidectomía total continúa siendo nuestra forma preferida de tratamiento para cáncer tiroideo.

\section{References}

1. Kocher, T.: Zur Pathologie und Therapie des Kropfes. Dtsch. Z. Chirug. 4:417, 1874

2. Halsted, W.S.: The operative story of goiter. The author's operation. Johns Hopkins Rep. 19:71, 1920

3. Lahey, F.H.: Routine dissection and demonstration recurrent laryngeal nerve in subtotal thyroidectomy. Surg. Gynecol. Obstet. 66:775, 1938

4. Crile, G.W.: The prevention of abductor paralysis in thyroidectomy. Surg. Gynecol. Obstet. 49:538, 1929

5. Riddell, v.H.: Injury to recurrent laryngeal nerves during thyroidectomy. Lancet $1: 638,1956$

6. Thompson, N.W., Harness, J.K.: Complication of total thyroidectomy for carcinoma. Surg. Gynecol. Obstet. $131: 861,1970$

7. Karlan, M.S., Catz, B., Dunkelman, D., Uyeda, R.Y., Gleischman, S.: A safe technique for thyroidectomy with complete nerve dissection and parathyroid preservation. Head Neck Surg. 6:1014, 1984

8. Barraclough, B.H., Reeve, T.S.: Postoperative complications of thyroidectomy: A comparison of 2 series at an interval of 10 years. Aust. N.Z. J. Surg. 45:21, 1975

9. Clark, O.H.: Total thyroidectomy: The treatment of choice for patients with differentiated thyroid cancer. Ann. Surg. 196:361, 1982

10. Jacobs, J.K., Aland, J.W., Ballinger, J.F.: Total thyroidectomy: A review of 213 patients. Ann. Surg. 197:542, 1983.

11. Loré, J.M., Kim, D.J., Ellias, S.: Preservation of the laryngeal nerves during total thyroid lobectomy. Ann. Otol. 86:777, 1977

12. Scanlon, E.F., Kellogg, J.E., Winchester, D.P., Larson, R.H.: The morbidity of total thyroidectomy. Arch. Surg. 116:568, 1981

13. Mountain, J.C., Stewart, G.R., Colock, B.P.: The recurrent laryngeal nerve in thyroid operations. Surg. Gynecol. Obstet. 133:978, 1971

14. Starnes, H.F., Brooks, D.C., Pinkus, G.S., Brooks, J.R.: Surgery for thyroid carcinoma. Cancer 55:1376, 1985

15. Martensson, J.H., Ternins, J.: Recurrent laryngeal nerve palsy in thyroid gland surgery related to operations and nerves at risk. Arch. Surg. 120:475, 1985

16. Wade, J.S.H.: Vulnerability of the recurrent laryngeal nerves at thyroidectomy. Br. J. Surg. 43:164, 1955

17. Loré, J.M.: Practical anatomical considerations in thyroid tumor surgery. Arch. Otolaryngol. 109:568, 1983

18. Riddell, V.: Thyroidectomy: Prevention of bilateral recurrent nerve palsy. Br. J. Surg. 57:1, 1970

19. Thompson, N.W., Olsen, W.R., Hoffman, G.L.: The continuing development of the technique of thyroidectomy. Surgery 73:913, 1973

20. Wijetilaka, S.E.: Non-recurrent laryngeal nerve. Br. J. Surg. 65:179, 1978

21. Sanders, G., Uyeda, R.Y., Karlan, M.S.: Nonrecurrent inferior nerves and their association with a recurrent branch. Am. J. Surg. 146:501, 1983 